\title{
Pengembangan Media Pembelajaran Interaktif Macromedia Flash 8 pada Pembelajaran Tematik Tema Pengalamanku
}

\author{
Mar'atush Sholichah Muntaha Rahmi ${ }^{*}$, M. Arif Budiman ${ }^{2}$, Ari Widyaningrum ${ }^{3}$ \\ ${ }^{123}$ Universitas PGRI Semarang Indonesia
}

\author{
ARTICLEINFO \\ Article history: \\ Received 18 February \\ 2019 \\ Received in revised form \\ 20 March 2019 \\ Accepted 20 April 2019 \\ Available online 20 May \\ 2019 \\ Kata Kunci: \\ Pengembangan, \\ Macromedia Flash 8, \\ validasi \\ Keywords: \\ Development, Macromedia \\ Flash 8, validation
}

\begin{abstract}
A B S T R A K
Penelitian ini menggunakan metodologi penelitian Research and Development (R\&D). Langkah-langkah untuk mengembangkan media interaktif berbasis macromedia flash 8 menggunakan prosedur pengembangan model Borg and Gall.Kevalidan media diperoleh dari hasil validasi ahli yang terdiri dari dua ahli media dan dua ahli materi. Hasil yang diperoleh dari ahli materi I 98,33\% dan ahli materi II 90\% . Hasil yang diperoleh ahli media I 97,5\% dan ahli media II 100\% dengan kriteria "Sangat Layak Digunakan". Kepraktisan media diperoleh melalui angket tanggapan siswa dan guru kelas II SDN Sidomulyo, SDN 1 Babadan dan SDN Purworejo terhadap media interaktif berbasis macromedia flash 8. Hasil angket tanggapan siswa kelas II SDN Sidomulyo 98,73\%, SDN 1 Babadan 98,88\%, dan SDN Purworejo $100 \%$. Hasil angket tanggapan guru kelas II SDN Sidomulyo 97,5\%, SDN 1 Babadan 97,5\% dan SDN Purworejo 100\% dengan kriteria "Sangat Layak Digunakan". Kesimpulan bahwa media interaktif berbasis macromedia flash 8 valid dan praktis digunakan pada tema pengalamanku kelas II Sekolah Dasar.
\end{abstract}

\section{A B S T R A C T}

This research used Research and Development ( $R \& D$ ) research methodology. The steps to develop an interactive media based on Macromedia Flash 8 using the procedure of developing the Borg and Gall model. Evaluation and media were obtained from the results of expert validation consisted of two media experts and two material experts. The results that obtained from first expert were $98.33 \%$ and second expert was $90 \%$. The results obtained by media experts were $97.5 \%$ and a second media expert was $100 \%$ with "Very Worthy of Use" criteria. The practicality of the media obtained through questionnaire responses from students and teachers of second class SDN Sidomulyo, SDN 1 Babadan and SDN Purworejo to interactive media based on macromedia flash 8. The results of the questionnaire responses of second class at SDN Sidomulyo was $98.73 \%$, SDN 1 Babadan was $98.88 \%$, and SDN Purworejo $100 \%$. The results of the questionnaire responses of second grade teachers at SDN Sidomulyo were 97.5\%, SDN 1 Babadan 97.5\% and SDN Purworejo $100 \%$ with the criteria "Very Worthy of Use". The conclusion is that interactive media based on Macromedia Flash 8 valid and practical used in the theme of my experience in class II Elementary School.

\footnotetext{
${ }^{1}$ Corresponding author.

E-mail addresses: Sholichah123@gmail.com (Mar'atush Sholichah Muntaha Rahmi)
} 


\section{Pendahuluan}

Pasal 1 UU SISDIKNAS no. 20 tahun 2003 disebutkan bahwa Sistem Pendidikan Nasional adalah keseluruhan komponen pendidikan yang saling terkait secara terpadu untuk mencapai tujuan pendidikan nasional. Berangkat dari bunyi pasal ini dapat diketahui bahwa pendidikan adalah sistem yang merupakan suatu totalitas struktur yang terdiri dari komponen yang saling terkait dan secara bersama menuju kepada tercapainya tujuan (Soetarno, 2003: 2). Adapun komponen-komponen dalam pendidikan nasional antara lain adalah lingkungan, sarana-prasarana, sumberdaya, dan masyarakat. Komponen-komponen tersebut bekerja secara bersama-sama, saling terkait dan mendukung dalam mencapai tujuan pendidikan (Munirah, 2015).

Pendidikan adalah hal terpenting bagi setiap negara untuk dapat berkembang pesat. Negara yang hebat akan menempatkan pendidikan sebagai prioritas pertamanya, karena dengan pendidikan, kemiskinan pada rakyat di negara tersebut akan dapat tergantikan menjadi kesejahteraan. Bagaimanapun, dalam perkembangannya, pendidikan di Indonesia senantiasa harus menghadapi beberapa masalah di setiap tahapnya. Masalahmasalah tersebut hanya dapat diselesaikan dengan partisipasi dari semua pihak yang terkait di dalam sistem pendidikan, seperti orangtua, guru-guru, kepala sekolah, masyarakat, dan juga peserta didik itu sendiri (Megawati, 2014).

Pendidikan lebih dari sekedar pengajaran, yang dapat dikatakan sebagai suatu proses transfer ilmu, transformasi nilai, dan pembentukan kepribadian dengan segala aspek yang dicakupnya. Dengan demikian pengajaran lebih berorientasi pada pembentukan spesialis atau bidangbidang tertentu, oleh karena itu perhatian dan minatnya lebih bersifat teknis. Pendidikan merupakan suatu proses yang diperlukan untuk mendapatkan keseimbangan dan kesempurnaan dalam perkembangan individu maupun masyarakat. Penekanan pendidikan dibanding dengan pengajaran terletak pada pembentukan kesadaran dan kepribadian individu atau masyarakat di samping transfer ilmu dan keahlian. Dengan proses semacam ini suatu bangsa atau negara dapat mewariskan nilai-nilai keagamaan, kebudayaan, pemikiran dan keahlian kepada generasi berikutnya, sehingga mereka betul-betul siap menyongsong masa depan kehidupan bangsa dan negara yang lebih cerah. Pendidikan juga merupakan sebuah aktifitas yang memiliki maksud atau tujuan tertentu yang diarahkan untuk mengembangkan potensi yang dimiliki manusia baik sebagai manusia ataupun sebagai masyarakat dengan sepenuhnya (Nurkholis, 2013).

Pendidikan menjadi hal yang penting bagi kehidupan seseorang untuk menentukan masa depan. Dengan pendidikan masa depan seseorang akan lebih terjamin karena melalui pendidikan seseorang dapat mengetahui potensi yang dimilikinya. Untuk itu pendidikan harus mempunyai kualitas yang baik agar mampu mendukung terbentuknya sumber daya manusia yang bermutu.

Dalam penelitian yang berjudul "Pengembangan Media Pembelajaran IPS Berbantuan Macromedia Flash 8.0 Pada Siswa Kelas III SD Negeri Ngupasan Tahun Ajaran 2016/2017" Mumpuni menyatakan Pendidikan merupakan unsur yang sangat penting dalam kehidupan manusia. Pendidikan serta ilmu pengetahuan dan teknologi (iptek) mempunyai kaitan yang sangat erat. Iptek menjadi bagian utama dalam isi pengajaran, dengan kata lain, pendidikan berperan sangat penting dalam pewarisan dan pengembangan iptek. Untuk meningkatkan kualitas pendidikan diperlukan adanya inovasi-inovasi baru dalam kegiatan pembelajaran. Soegeng (2012: 4) menyatakan Pendidikan adalah proses dimana seseorang mengembangkan kemampuan, sikap, dan bentuk-bentuk tingkah laku lainnya didalam masyarakat, dimana dia hidup. Dari pengertian diatas dapat disimpulkan bahwa pengertian pendidikan adalah proses pengembangan potensi diri yang dimiliki untuk hidup didalam masyarakat.

Permendikbud Nomor 65 Tahun 2013 menyatakan bahwa proses pembelajaran pada satuan pendidikan diselenggarakan secara interaktif, inspiratif, menyenangkan, menantang, memotivasi peserta didik untuk berpartisipasi aktif, serta memberikan ruang yang cukup bagi prakarsa, kreatifitas, dan kemandirian sesuai dengan bakat, minat dan perkembangan fisik serta psikologis peserta didik.

Menurut Gagne dan Briggs dalam Kustandi (2011: 5) mengatakan media pembelajaran meliputi alat secara fisik digunakan untuk menyampaikan isi materi pengajaran, yang terdiri antara lain buku, tape recorder, kaset, video camera, video recorder, film, slide, foto, gambar, grafik, televisi dan komputer. Pengertian media pembelajaran menurut Sanaky (2013: 3) media pembelajaran adalah sebuah alat yang berfungsi dan dapat digunakan untuk menyampaikan pesan pembelajaran. Media pembelajaran merupakan faktor yang sangat penting dalam pembelajaran karena media pembelajaran berkaitan dengan pengalaman belajar siswa. Dengan menggunakan media pembelajaran dapat meningkatkan minat belajar siswa. Perkembangan teknologi yang pesat dapat dimanfaatkan dalam pengembangan media pembelajaran. Salah satunya penggunaan komputer dalam pengembangan media yang nantinya dapat digunakan untuk menyampaikan pesan pembelajaran.

Berdasarkan hasil wawancara dan observasi yang dilakukan peneliti di SD N Sidomulyo Kecamatan Kaliori Kabupaten Rembang dengan guru kelas II, menunjukkan bahwa terdapat permasalahan dalam 
penerapan pembelajaran yang masih menggunakan metode pembelajaran konvensional, seperti ceramah, demonstrasi dan penugasan. Selain itu kurangnya penggunaan media pembelajaran oleh guru disebabkan karena media disekolah sangat terbatas dan hanya menggunakan alat peraga sederhana dan seadanya. Jarangnya penggunaan media oleh guru juga disebabkan oleh kesibukan guru, sehingga guru tidak memiliki banyak waktu untuk membuat media pembelajaran. Kurangnya penggunaan media pembelajaran oleh guru akan berdampak pada kurang optimalnya daya tangkap siswa terhadap materi pelajaran yang mengakibatkan hasil belajar siswa rendah.

Berdasarkan permasalahan-permasalahan yang sudah dipaparkan diatas, peneliti perlu untuk membuat sebuah inovasi media pembelajaran tematik untuk kelas II yang dapat membantu siswa dalam memahami materi pembelajaran. Media pembelajaran tersebut bersifat interaktif agar siswa dapat berinteraksi dan menggunakannya secara langsung.

Semakin beragamnya media pengajaran, Raharjo mengatakan pemilihan media hendaknya memperhatikan beberapa prinsip. Yaitu; (a) Kejelasan maksud dan tujuan pemilihan media; apakah untuk keperluan hiburan, informasi umum, pembelajaran dan sebagainya, (b) Familiaritas media, yang melibatkan pengetahuan akan sifat dan ciri-ciri media yang akan dipilih, dan (3) Sejumlah media dapat diperbandingkan karena adanya beberapa pilihan yang kiranya lebih sesuai dengan tujuan pengajaran.14 Banyak penelitian diadakan mengenai media pembelajaran mana yang paling sesuai untuk tujuan tertentu, dan hasil penelitian menunjukan bahwa; 1) Tidak setiap media pengajaran dapat dimanfaatkan untuk mencapai sembarang tujuan pengajaran, 2) Semua media pengajaran dapat membantu guru dalam melaksanakan satu atau beberapa fungsi dalam pengajaran, seperti mengisahkan, mengontrol/mengecek, memberikan penguatan dan mengadakan evaluasi. Bahkan ada kemungkinan, media itu mengambil alih fungsi itu misalnya film yang mengisahkan proses pertumbuhan sel.15 Lebih lanjut Winkel mengatakan bahwa pemilihan media disamping melihat kesesuiannya dengan tujuan intruksional khusus, materi pelajaran, prosedur didaktis dan bentuk pengelompokan siswa, juga harus dipertimbangkan soal biaya (cost factor), ketersediaan peralatan waktu dibutuhkan (avaibility factor), ketersediaan aliran listrik, kualitas teknis (technical cuality), ruang kelas, dan kemampuan guru menggunakan media secara tepat (technical know-how) (Mahnun, 2012).

Media Pembelajaran adalah sarana untuk meningkatkan kegiatan proses belajar mengajar. (Kustandi, Sutjipto, 2011:8) Media Pembelajaran yaitu alat yang dapat membantu proses belajar mengajar dan berfungsi untuk memperjelas makna pesan yang disampaikan, sehingga dapat mencapai tujuan pembelajaran dengan lebih baik dan sempurna.

Ariani dan Dany (2010) menjelaskan bahwa "multimedia adalah hasil perpaduan antara berbagai media yang berupa teks, gambar, grafik, sound, animasi, dan video yang digunakan untuk menyampaikan pesan kepada publik". Macromedia flash merupakan salah satu multimedia yang dapat membuat video, animasi, gambar, dan suara dengan cara yang mudah dan efektif. Dengan menggunakan multimedia, hal yang abstrak dapat dikonkritkan sehingga dapat ditampilkan ke hadapan siswa dan menarik minat belajarnya melalui berbagai bentuk animasi yang disajikan (Fakhri, 2018).

Menurut Hadi, sebagaimana dikutip oleh Firdaus (2012:21-24) Macromedia Flash adalah software aplikasi untuk animasi yang digunakan untuk internet dengan demikian dapat digunakan pada pengembangan multimedia interaktif untuk produksi $C D$, jaringan maupun penggunaan pada web. Dalam multimedia dapat dilihat teks, gambar, animasi dan digital video bersama-sama tampil pada satu saat dan penggunaan botton sebagai alat interaktif (Samsudi, 2015).

Menurut Hakim (2004) dalam (Rena Lestari 2014) Macromedia Flash adalah program untuk membuat animasi dan aplikasi web profesional. Bukah hanya itu, macromedia flash juga banyak digunakan untuk membuat game, animasi kartun, dan aplikasi multimedia interaktif seperti demo produk dan tutorial interaktif. Macromedia flash merupakan kumpulan gambar yang diolah sedemikian rupa sehingga menghasilkan gerakan.

Menurut uraian permasalahan diatas, maka penulis perlu melakukan penelitian pengembangan yang berjudul "Pengembangan Media Pembelajaran Interaktif Macromedia Flash 8 Pada Pembelajaran Tematik Tema Pengalamanku Kelas II Sekolah Dasar".

\section{Metode}

Jenis penelitian yang digunakan pada penelitian ini adalah penelitian dan pengembangan atau Research and Development (R\&D). "Metode penelitian dan pengembangan atau dalam bahasa Inggrisnya Research and Development adalah metode penelitian yang digunakan untuk menghasilkan produk tertentu, dan menguji keefektifan produk tersebu". (Sugiyono, 2015:407)

Prosedur penelitian dan pengembangan disesuaikan dengan prosedur yang ditentukan oleh buku pedoman skripsi dengan menggunakan langkah-langkah yang dikemukakan oleh Borg \& Gall, 
sebagaimana siklus Reseacrh and Development (R\&D). Tahap uji coba awal dilakukan pada 1-3 sekolah yang melibatkan 6-12 subjek dan data hasil wawancara dan angket dikumpulkan dan dianalisis. Uji coba dilakukan di 3 sekolah yaitu SD N Sidomulyo, SD N 1 Babadan, dan SD N Purworejo dengan melibatkan siswa kelas II sebagai uji coba lapangan awal diterima atau tidaknya tentang pengembangan media Macromedia Flash 8 tema Pengalamanku.

Penelitian ini menggunakan dua teknik analisis data yaitu analisis deskriptif kualitatif dan analisis deskriptif kuantitatif. Data kualitatif berupa tanggapan dan saran perbaikan produk dari ahli materi pembelajaran dan ahli media pembelajaran yang kemudian produk tersebut diperbaiki dan dikembangkan.

Data kuantitatif berupa skor penilaian instrumen validasi materi dan media, skor penilaian ahli media, skor penilaian ahli materi, skor tanggapan siswa terhadap media interaktif macromedia flash 8 , dan skor tanggapan guru terhadap media interaktif macromedia flash 8. Skor tersebut diperoleh melalui angket. Penilaian kevalidan media interaktif berbasis macromedia flash 8 diperoleh dari penilaian validasi ahli media dan ahli materi.

Tabel 1. Range Presentasi dan Kriteria Kualitatif

\begin{tabular}{cl}
\hline Range $(\%)$ & Kriteria Kualitatif \\
\hline $0-40$ & Sangat tidak layak digunakan \\
$41-60$ & Tidak layak digunakan \\
$61-80$ & Layak digunakan \\
$81-100$ & Sangat layak digunakan \\
\hline
\end{tabular}

Pada hasil validasi ahli media dan materi dikatakan valid apabila hasil berada pada rentang $81 \%$ 100\% dengan kriteria "Sangat Layak", rentang 61\%-80\% dengan kriteria "Layak", rentang 41\%-60\% dengan kriteria "Tidak Layak", dan rentang 0\%-40\% dengan kriteria "Sangat Tidak Layak".

Hasil tanggapan guru terhadap media interaktif berbasis macromedia flash 8 digunakan untuk menganalisis data dari lembar angket tanggapan guru dengan skala Likert bentuk checklist dilakukan dengan perhitungan yang sama dengan cara penilaian pada angket kevalidan.

Hasil penilaian tanggapan siswa terhadap media interaktif berbasis macromedia flash 8 dengan skala Guttman yang berupa "Ya-Tidak" diubah menjadi angka.

Tabel 2. Penskoran Angket Tanggapan Siswa

\begin{tabular}{ll}
\hline Tanggapan Siswa & Skor \\
\hline Ya & 1 \\
Tidak & 0 \\
\hline
\end{tabular}

$$
\text { Presentase }=\frac{\text { Jumlah skor ideal }}{\text { Skor } \text { ideal }} \times 100 \%
$$

Presentase tersebut menunjukkan tingkat keidealan media interaktif berbasis macromedia flash 8 berdasarkan penilaian tanggapan guru dan siswa kelas II.

\section{Hasil dan Pembahasan}

Tahap pertama pada penelitian ini yaitu peneliti melakukan studi pendahuluan melalui observasi, wawancara, dan angket terhadap siswa dan guru kelas II SDN Sidomulyo, SDN 1 Babadan dan SDN Purworejo tujuannya untuk menemukan permasalahan terkait dengan pembelajaran yang terjadi pada Sekolah Dasar tersebut. Yang kemudian permasalahan dapat dianalisis peneliti untuk menciptakan sebuah inovasi baru yaitu dengan menciptakan sebuah media pembelajaran yang dapat membantu siswa dan guru dalam pembelajaran.

Selain wawancara, peneliti juga melakukan analisis terhadap kebutuhan sekolah dengan memberikan angket untuk siswa dan guru yang menjadi bagian dari studi pendahuluan. Hal ini dilakukan untuk mengetahui gambaran kebutuhan media interaktif berbasis macromedia flash 8. Dari data tersebut, diketahui bahwa kebutuhan siswa terhadap media interaktif berbasis macromedia flash 8 sangat diperlukan. Hasil angket analisis kebutuhan siswa yang terdapat di tiga Sekolah Dasar di Kecamatan Kaliori Kabupaten Rembang, yaitu SDN Sidomuluyo, SDN 1 Babadan, dan SDN Purworejo dengan 
responden sebanyak 66 siswa sebagai berikut: (1) 100\% siswa suka dengan penyampaian materi yang diajarkan oleh guru; (2) 31,81\% siswa menyatakan guru sering menggunakan media saat menyampaikan materi pelajaran dan $68,18 \%$ siswa menyatakan guru tidak menggunakan media saat menyampaikan materi pelajaran; (3) 89,39\% siswa menyatakan media dapat membantu mempermudah dalam menyerap materi pelajaran, dan $10,60 \%$ siswa menyatakan media pembelajaran tidak dapat membantu mempermudah dalam menyerap materi pelajaran; (4) 93,93\% siswa senang jika guru menggunakan media pembelajaran, dan 6,06\% siswa tidak senang jika guru menggunakan media pembelajaran; (5) $96,96 \%$ siswa menyatakan suka game tentang materi pelajaran dan 3,03\% siswa menyatakan tidak suka game tentang materi pelajaran; (6) $27,27 \%$ siswa menyatakan guru pernah menggunakan media interaktif berbasis macromedia flash 8 , dan $72,72 \%$ siswa menyatakan guru tidak pernah menggunakan media interaktif berbasis macromedia flash 8, (7) 89,39\% siswa suka media pembelajaran yang memunculkan suara dan $10,60 \%$ siswa tidak suka media pembelajaran yang memunculkan suara; (8) $77,27 \%$ siswa suka media dengan gambar dan $22,72 \%$ siswa tidak suka media dengan gambar; (9) $81,81 \%$ siswa suka dengan tampilan media yang berwarna-warni dan $18,18 \%$ siswa tidak suka dengan tampilan media yang berwarna-warni; (10) 96,96\% siswa menyatakan perlu dibuat media interaktif berbasis macromedia flash 8 dan 3,03\% siswa menyatakan tidak perlu dibuat media interaktif berbasis macromedia flash 8. Selain angket analisis kebutuhan kepada siswa, peneliti juga memberikan angket analisis kebutuhan kepada guru.

Pengisian angket kebutuhan guru dilakukan oleh tiga guru kelas II di Kecamatan Kaliori Kabupaten Rembang, yaitu Bu Iin Yulianawati, S.Pd dari SDN Sidomulyo, Bapak Rusdi, S.Pd dari SDN 1 Babadan dan Bapak Zhebta D Banyukuning, S.Pd dari SDN Purworejo. Berdasarkan data tersebut diketahui bahwa angket analisis kebutuhan guru yang dilakukan di tiga Sekolah Dasar yaitu SDN Sidomulyo, SDN 1 Babadan, dan SDN Purworejo dengan responden 3 guru kelas II sebagai berikut: (1) 100\% pembelajaran pada tema pengalamanku yang dilakukan guru sudah sesuai dengan kompetensi inti dan kompetensi dasar; (2) 100\% pembelajaran pada tema pengalamanku menyenangkan bagi siswa; (3) 33,33\% guru sudah memiliki media tematik untuk mengajarkan materi pada tema pengalamanku dan $66,66 \%$ belum memiliki koleksi media tematik untuk mengajarkan materi pada tema pengalamanku; (4) 66,66\% guru dalam mengajarkan materi pengalamanku mengalami kendala dalam memilih media yang menyenangkan bagi siswa, dan 33,33\% tidak mengalami kendala dalam memilih media yang menyenangkan bagi siswa; (5) $100 \%$ guru membutuhkan alternatif media pembelajaran pada tema pengalamanku; (6) $100 \%$ guru pernah menggunakan media interaktif untuk menyampaikan materi pada tema pengalamanku; (7) $100 \%$ guru menyatakan warna tampilan media interaktif berwarna-warni agar disukai oleh siswa; (8) 100\% guru menyatakan perlu dibuat game edukatif dalam media interaktif; (9) 100\% guru menyarankan sebaiknya media dilengkapi dengan musik; (10) 33,33\% guru sudah pernah melihat media interaktif berbasis macromedia flash 8 dan $66,66 \%$ guru belum pernah melihat media interaktif berbasis macromedia flash 8.

Tahap selanjutnya yaitu pengembangan produk dan perancangan media interaktif berbasis macromedia flash 8 yang disusun oleh peneliti yang nantinya menjadi sebuah media pembelajaran yang edikatif dan layak digunakan untuk kelas II Sekolah Dasar pada tema Pengalamanku yang berpedoman pada kompetensi inti dan kompetensi dasar kurikulum 2013. Dengan dikembangkannya media pembelajaran interaktif berbasis macromedia flash 8 tersebut siswa akan merasa senang dan antusias untuk mengikuti kegiatan pembelajaran. Karena pada media interaktif berbasis macromedia flash 8 isinya materi yang ditambah dengan tampilan bergambar dan ada musik sesuai dengan tema Pengalamanku.

Uji validasi media dilakukan oleh ahli media dan ahli materi. Berdasarkan hasil penilaian oleh ahli media dan ahli materi maka akan dilakukan perbaikan berdasarkan komentar dan saran yang diberikan oleh ahli media pembelajaran maupun ahli materi. Berikut hasil rekapitulasi angket validasi tahap pertama:

Tabel 2. Hasil Rekapitulasi Angket Validasi Tahap Pertama

No. Ahli Jumlah Nilai Nilai Maksimal Presentase Kriteria

\begin{tabular}{llllll}
\hline 1 & Ahli materi I & 55 & 60 & $91,66 \%$ & Sangat Layak digunakan \\
2 & Ahli materi II & 52 & 60 & $86,66 \%$ & Sangat Layak digunakan \\
\hline
\end{tabular}


Tabel 3. Validasi materi dan media dilakukan

\begin{tabular}{cccccc} 
No & Ahli & Jumlah Nilai & Nilai Maksimal & Presentase & Kriteria \\
\hline 1 & Ahli media I & 36 & 40 & $90 \%$ & Sangat Layak digunakan \\
2 & Ahli media II & 36 & 40 & $90 \%$ & Sangat Layak digunakan \\
\hline
\end{tabular}

Validasi materi dan media dilakukan dua tahap untuk tahap pertama sudah memenuhi criteria dan layak digunakan namun perlu dilakukan revisi. Dan untuk validasi tahap kedua hasil presentase yang diperoleh sebagai berikut:

Tabel 4. Hasil Rekapitulasi Angket Validasi Tahap Kedua

\begin{tabular}{cccccc}
\hline No. & \multirow{2}{*}{ Ahli } & Jumlah Nilai & Nilai Maksimal & Presentase & Kriteria \\
& & & & & \\
\hline 1 & Ahli materi I & 59 & 60 & $98,33 \%$ & Sangat Layak digunakan \\
2 & Ahli materi II & 52 & 60 & $86,66 \%$ & Sangat Layak digunakan \\
\hline
\end{tabular}

Tabel 5. hasil perhitungan angket tanggapan siswa diberikan

\begin{tabular}{cccccc}
\hline \multirow{2}{*}{ No. } & Ahli & Jumlah Nilai & Nilai Maksimal & Presentase & Kriteria \\
& & & & & \\
\hline 1 & Ahli media I & 39 & 40 & $97,5 \%$ & Sangat Layak digunakan \\
2 & Ahli media II & 39 & 40 & $97,5 \%$ & Sangat Layak digunakan \\
\hline
\end{tabular}

Dari hasil perhitungan angket tanggapan siswa diberikan dan diisi oleh seluruh siswa kelas II di tiga Sekolah Dasar, yaitu SDN Sidomulyo yang berjumlah 21 siswa, SDN 1 Babadan yang berjumlah 24 siswa, dan SDN Purworejo yang berjumlah 21 siswa terhadap media interaktif berbasis macromedia flash 8 didapatkan rata-rata hasil angket tanggapan siswa kelas II SDN Sidomulyo presentase sebesar 98,73\%, SDN 1 Babadan presentase sebesar 98,88\%, dan SDN Purworejo presentase sebesar 100\%. Setelah dikonversikan, presentase tersebut berada pada kualifikasi baik sekali.

Selain dari angket tanggapan siswa peneliti juga memberikan angket tanggapan yang diberikan kepada tiga guru yaitu Ibu Iin Yulianawati, S.Pd selaku guru kelas II SDN Sidomulyo, Bapak Rusdi, S.Pd selaku guru kelas II SDN 1 Babadan dan Bapak Zhebta D Banyukuning, S.Pd selaku guru SDN Purworejo.Hasil angket tanggapan guru kelas II SDN Sidomulyo diperoleh presentase sebesar 97,5\%, SDN 1 Babadan diperoleh presentase sebesar 97,5\% dan SDN Purworejo diperoleh presentase sebesar 100\% dengan kriteria "Sangat Layak Digunakan".

\section{Simpulan dan Saran}

Simpulan yang dapat diambil pada penelitian dan pengembangan ini yaitu kevalidan media interaktif berbasis macromedia flash 8 dapat dilihat dari presentasi hasil validasi terhadap media interaktif berbasis macromedia flash 8. Validasi dilakukan oleh tiga dosen Universitas PGRI Semarang, dimana setiap validator berperan sebagai ahli media dan materi. Hasil rata-rata penilaian yang diperoleh dari ahli media sebesar 98,75\% dengan kriteria "Sangat Layak digunakan", dan hasil rata-rata penilaian yang diperoleh ahli materi sebesar 94,16\% dengan kriteria "Sangat Layak digunakan". Sehingga dapat disimpulkan bahwa media interaktif berbasis macromedia flash 8 pada tema pengalamanku valid digunakan di kelas II Sekolah Dasar.

Kepraktisan media interaktif berbasis macromedia flash 8 diperoleh dari presentase hasil angket tanggapan siswa dan guru kelas II SDN Sidomulyo, SDN 1 Babadan, dan SDN Purworejo. Hasil rata-rata tanggapan siswa terhadap media interaktif berbasis macromedia flash 8 sebesar 99,20\%. Dan hasil tanggapan guru terhadap media interaktif berbasis macromedia flash 8 sebesar 98,33\%. Berdasarkan hasil 
tersebut, maka dapat disimpulkan bahwa media interaktif berbasis macromedia flash 8 pada tema pengalamanku praktis digunakan di kelas II Sekolah Dasar.

\section{Daftar Rujukan}

Anitah, Sri. 2010. Media Pembelajaran. Surakarta: Yuma Pressindo.

Arsyad, Azhar. 2014. Media pembelajaran. Jakarta: Rajawali Pers.

Daryanto. 2014 Pembelajaran Tematik, Terpadu, Terintegrasi (Kurikulum 2013). Yogyakarta: Gava Media.

Djamarah, Syaiful Bahri. Dan Aswan Zain. 2010. Strategi Belajar Mengajar. Jakarta: Rineka Cipta.

Fakhri, Isa. 2018. Penggunaan Media Pembelajaran Animasi Berbantuan Macromedia Flash Pada Pembelajaran Fisika Pokok Bahasan Momentum, Impuls, Dan Tumbukan Kelas X Sma. Jurnal Pembelajaran Fisika, Vol. 7 No. 3, September 2018, hal 271-277

Khairani, Majidah dan Febrinal, Dian. 2016. "Pengembangan Media Pembelajaran dalam Bentuk Macromedia Flash Materi Tabung untuk SMP kelas IX". Jurnal Ipteks Terapan, 10 (2).

Kurniawan, Deni. 2014. Pembelajaran Terpadu Tematik. Bandung: Alfabet

Kustandi, Cecep. Dan Bambang Sutjipto. 2011. Media Pembelajaran Manual dan Digital. Jakarta: Ghalia Indonesia.

Lestari, Rena. 2004. "Pengembangan Media Pembelajaran Pembelahan Sel dengan Menggunakan Macromedia Flash untuk Kelas XII SMA". Jurnal Ilmiah Edu Research, 3 (2), 133-138.

Mahnun, Nunu. 2012. Media Pembelajaran (Kajian Terhadap Langkah-Langkah Pemilihan Media Dan Implementasinya Dalam Pembelajaran) . Jurnal Pemikiran Islam; Vol. 37, No. 1 Januari-Juni 2012

Megawati. 2014. Meretas Permasalahan Pendidikan Di Indonesia . Jurnal Formatif 2(3): 227-234 ISSN: 2088-351X

Mulyasa. 2013. Pengembangan dan Implementasi Kurikulum 2013. Bandung: Remaja Rosdakarya.

Mumpuni, Olivia Cikal. 2017. "Pengembangan Media Pembelajaran IPS Berbantuan Macromedia Flash 8.0 Pada Siswa Kelas III SD Negeri Ngupasan Tahun Ajaran 2016/2017". Jurnal PGSD Indonesia, 3 (1).

Munadi, Yudhi. 2013. Media Pembelajaran (Sebuah Pendekatan Baru). Jakarta: Referensi (GP Press Group).

Munirah. 2015. Sistem Pendidikan Di Indonesia: Antara Keinginan Dan Realita . Jurnal Auladuna, Vol. 2 No. 2 Desember 2015: 233-245

Noviana. 2013. "Pengembangan Media Pembelajaran Melalui Macromedia Flash Dalam Meningkatkan Kompetensi Membaca Puisi Siswa Kelas V di MIN Malang 1". NOSI, 1 (7), 697-705.

Nurkholis . 2013. Pendidikan Dalam Upaya Memajukan Teknologi . Jurnal Kependidikan, Vol. 1 No. 1 Nopember 2013

Permendikbud No 65 Tahun 2013 tentang Standar Proses Pendidikan Dasar dan Menengah.

Sanaky, Hujair A.H. 2013. Media Pembelajaran Interaktif-Inovatif. Yogyakarta: Kaukaba.

Samsudi. 2015. Penerapan Media Interaktif Berbasis Macromedia Flash Pada Kompetensi Dasar Memelihara Transmisi Otomatis Dan Komponennya Untuk Meningkatkan Hasil Belajar . Jurnal Pendidikan Teknik Mesin Vol. 15, No. 2, Desember 2015 (78-81)

Sanjaya, Wina. 2014. Media Komunikasi Pembelajaran. Jakarta: Prendamedia Grup. 
Soegeng, dkk. 2012. Pengantar Ilmu Pendidikan. Semarang: IKIP PGRI SEMARANG PRES.

Sukmadinata, Nana Syaodih. 2016. Metode Penelitian Pendidikan. Bandung: Remaja Rosdakarya.

Sugiyono. 2017. Metode Penelitian Pendidikan Pendekatan (Kuantitatif, Kualitatif, dan RND). Bandung: Alfabeta.

Wiyani, Novian Andy. 2013. Desain Pembelajaran Pendidikan (Tata Rancang Pembelajaran Menuju Pencapaian Kompetensi). Yogyakarta: Ar-Ruzz Media.

Yudhiantoro, D. 2006. Macromedia Flash Professional 8. Yogyakarta. Andi. 